\title{
Correction to: Neuroendocrine Liver Metastasis: Prognostic Implications of Primary Tumor Site on Patients Undergoing Curative Intent Liver Surgery
}

\author{
Gaya Spolverato ${ }^{1} \cdot$ Fabio Bagante $^{1} \cdot$ Luca Aldrighetti $^{2} \cdot$ George Poultsides $^{3} \cdot$ Todd W. Bauer $^{4} \cdot$ Ryan C. Fields $^{5}$. \\ Hugo P. Marques ${ }^{6} \cdot$ Matthew Weiss $^{7} \cdot$ Shishir K. Maithel ${ }^{8} \cdot$ Timothy M. Pawlik $^{9}$
}

Published online: 16 September 2019

(C) 2019 The Society for Surgery of the Alimentary Tract

\section{Correction to: J Gastrointest Surg} https://doi.org/10.1007/s11605-017-3491-1

There is an error in an author's name in this paper, Ryan C. Field should be Ryan C. Fields. The correct author list is above.

Publisher's Note Springer Nature remains neutral with regard to jurisdictional claims in published maps and institutional affiliations.

The online version of the original article can be found at https://doi.org/ 10.1007/s11605-017-3491-1

Timothy M. Pawlik

tim.pawlik@osumc.edu

Department of Surgery, University of Verona, Verona, Italy

2 Scientific Institute San Raffaele, Milan, Italy

3 Stanford University, Stanford, CA, USA

4 University of Virginia, Charlottesville, VA, USA

5 School of Medicine, Washington University, St Louis, MO, USA

6 Curry Cabral Hospital, Lisbon, Portugal

7 Johns Hopkins Hospital, Baltimore, MD, USA

8 Emory University, Atlanta, GA, USA

9 Department of Surgery, The Ohio State University Comprehensive Cancer Center, Columbus, OH, USA 